\title{
Genetic diversity in the germplasm of black pepper determined by EST-SSR markers
}

\author{
B.D. $\mathrm{Wu}^{1,2}$, R. Fan ${ }^{1,2}$, L.S. $\mathrm{Hu}^{1,2}$, H.S. $\mathrm{Wu}^{1,2}$ and C.Y. Hao ${ }^{1,2}$ \\ ${ }^{1}$ Spice and Beverage Research Institute, \\ Chinese Academy of Tropical Agricultural Sciences, Wanning, Hainan, China \\ ${ }^{2}$ Key Laboratory of Genetic Resources Utilization of Spice and Beverage Crops, \\ Ministry of Agriculture, Wanning, Hainan, China
}

Corresponding author: C.Y. Hao

E-mail: haochy79@163.com

Genet. Mol. Res. 15 (1): gmr.15018099

Received November 19, 2015

Accepted January 22, 2016

Published March 18, 2016

DOI http://dx.doi.org/10.4238/gmr.15018099

ABSTRACT. This study aimed to assess genetic diversity in the germplasm of black pepper from around the world using SSR markers from EST. In total, 13 markers were selected and successfully amplified the target loci across the black pepper germplasm. All the EST-SSR markers showed high levels of polymorphisms with an average polymorphism information content of 0.93 . The genetic similarity coefficients among all accessions ranged from 0.724 to 1.000 , with an average of 0.867 . These results indicated that black pepper germplasms possess a complex genetic background and high genetic diversity. Based on a cluster analysis, 148 black pepper germplasms were grouped in two major clades: the Neotropics and the Asian tropics. Peperomia pellucida was grouped separately and distantly from all other accessions. These results generally agreed with the genetic and geographic distances. However, the Asian tropics clade did not cluster according to their geographic origins. In addition, compared with the American accessions, the Asian wild accessions and cultivated accessions grouped together, indicating a close genetic relationship. This verified the 
origin of black pepper. The newly developed EST-SSRs are highly valuable resources for the conservation of black pepper germplasm diversity and for black pepper breeding.

Key words: Black pepper; Germplasms; EST-SSR; Polymorphism; Genetic diversity

\section{INTRODUCTION}

Black pepper (Piper nigrum L., $2 n=4 x=52$ ) is one of the most valuable and economically important spice crops. Geographically, black pepper originated from the Western Ghats in south India, but later spread to Indonesia, Malaysia, and other pepper producing countries (Ranvindran, 2000). P. nigrum, now adapted to a wide range of environmental conditions, grows in a vast altitudinal region. The variation in ecological characteristics has led to great inter-species diversity (Howard, 1973). Black pepper was cultivated widely on the Asian continent, because of the humid climatic conditions and the daily consumption in the diet. Black pepper was traditionally used as a medicine for its antioxidant, anti-inflammatory, and anticancer properties (Liu et al., 2010; Nishimura et al., 2011). Currently, black pepper is widely utilized in medicine, food industry, the military, etc. In 1947, black pepper was introduced into the Chinese Hainan Province from Indonesia. China has since grown into one of the main black pepper producing countries. The cultivating area is currently greater than $3 \times 10^{4}$ ha and the production is $>3 \times 10^{4}$ tons annually, making China the fifth ranking country in the world in terms of total yield (Wu et al., 2009). However, there is a disequilibrium due to the strong demand and insufficient supply in the market of China. By 2003, the average annual imports reached $0.3 \times 10^{4}$ tons, the top imports reach to $1.0 \times 10^{4}$ tons by far.

Phytophthora foot rot disease has been recognized as one of the most devastating diseases for pepper. The infected plants generally show the symptoms leaf yellowing and dropping of branches, which eventually results in plant death. Every year, farmers need to replant to compensate for loss of plants due to the foot rot disease. Foot rot disease has caused severe economic damage in many countries (Anandaraj, 2000). To date, researchers have not developed an efficient management method for controlling this disease. Some wild species (Piper colubrinum and Piper hainanense) have been considered to display high resistance to Piper capsici (Fan et al., 2015). Many black pepper germplasms have been collected, including wild pepper and cultivated varieties from Asia and America. It is sometimes difficult to study the genetic variability of black pepper germplasms, based on morphological characters. Little is known about the genetic variability of the collected material at the DNA level. In order to exploit the genetic diversity of the black pepper germplasm, it is therefore necessary to study it more in depth.

For efficient management, conservation, and utilization of germplasm, it is crucial to assess genetic diversity using molecular markers. Some studies of the genetic diversity of black pepper germplasms have been performed using DNA markers. The genetic diversity of the genus Piper in Hainan has been analyzed using ISSR, RAPD, and SRAP markers. The high genetic diversity in Jianfengling and Diaoluoshan demonstrate that conservation efforts for the genus Piper in these two localities are more effective than those in other localities in Hainan (Jiang and Liu, 2011a,b). Based on ISSR markers, 56 accessions of black pepper collected from Asia and America could be divided into three groups corresponding to their geographic distribution (Fan et al., 2014). Seven new SSR primers were generated to analyze the genetic diversity of 40 popular cultivars and four species of black pepper in the southern region of India (Joy et al., 2011). Compared with AFLP, 
RAPD, and ISSR maters, EST-SSR (EST-derived SSR) markers have the advantages of simplicity, effectiveness, and reproducibility. They are also easily detected by polymerase chain reaction (PCR). They have a higher transferability to related species compared to SSRs (Zhang et al., 2013). For the genus Piper, EST-SSR markers are more effective and reproducible than random amplified DNA markers and cheaper than SSR markers. Based on the black pepper transcriptome (NCBI accession No. SRX119532), EST-SSR markers have been successfully developed and applied to the genus Piper (Wu et al., 2015). Yet, EST-SSR studies of the genetic diversity of genus Piper have not previously been reported.

In the present study, we extend the analysis of genetic diversity in black pepper germplasm with 148 accessions, including wild species and black pepper varieties from Asia and the Americas, using transcriptome EST-SSR markers. Knowledge of the genetic variation of black pepper germplasm is important for its efficient use in breeding or grafting programs, and for conservation purposes. The results may be of use in the conservation of black pepper diversity and breeding.

\section{MATERIAL AND METHODS}

\section{Plant material}

A total of 148 wild species and varieties were used in this study (Table S1), including 104 wild species from Asia, 10 wild pepper from the Americas, 33 varieties from different countries, and one accession of Peperomia pellucida. These black pepper germplasms were collected from the National Black Pepper Germplasm Repository in Wanning City, Hainan Province of China.

\section{Development of EST-SSR primers}

Three transcriptomes of $P$. nigrum and Piper flaviflorum have been produced by our research group (NCBI accession Nos. SRX890122 and SRX708503). These were used to screen SSR motifs that harbor at least five repeats with di-, tri-, tetra-, penta-, or hexa-nucleotides, using the MISA software (MlcroSAtellite, http://pgrc.ipk-gatersleben.de/misa/) (Hu et al., 2015; Hao CY, Xia ZQ, Fan R, Tan LH, et al., unpublished results).

The Primer Premier 6.0 software (PREMIER Biosoft International, Palo Alto, CA, USA) was used to design the EST-SSR primers. The primer design complies with the rules as follows: The optimal annealing temperature was around $60^{\circ} \mathrm{C}$, and the amplified fragments ranged from 80 to $300 \mathrm{bp}$. The primers were filtered out, when aligned to more than one UniGene, or more than three mismatches in the 5' site and one mismatch in the 3' site aligned to the SSR-containing sequences. Primers were synthesized by Sangon Biotech Co., Ltd (Shanghai, China).

\section{DNA extraction and PCR amplification}

Genomic DNA of the panel accessions was extracted from young leaves using D248501 E.Z.N.A. HP Plant DNA Kit (OMEGA, Stamford, CT, USA), according to the manufacturer instructions. Target products were generated using the EST-SSR primers. The PCR was performed in a $20-\mu \mathrm{L}$ total reaction volume. The PCR mixture comprised 20 ng genomic DNA, $2 \mu \mathrm{L} 10 \mathrm{X}$ Taq buffer with $(\mathrm{NH} 4)_{2} \mathrm{SO}_{4}, 1.2 \mu \mathrm{L} \mathrm{MgCl}(25 \mathrm{mM}), 0.5 \mu \mathrm{L}$ each primer $(10 \mu \mathrm{M}), 0.4 \mu \mathrm{L}$ dNTP mix (10 mM) (MBI Fermentas, Burlington, Ontario, Canada), and $1 \mathrm{U}$ of Taq DNA polymerase (MBI Fermentas). The PCR was performed in a thermocycler (Agilent SureCycler 8800 Gradient Cycler, 
Santa Clara, CA, USA) with the following program: an initial denaturation of $94^{\circ} \mathrm{C}$ for $5 \mathrm{~min}$; 35 cycles of $94^{\circ} \mathrm{C}$ for $60 \mathrm{~s}$, annealing at $53^{\circ} / 55^{\circ} \mathrm{C}$ for $60 \mathrm{~s}$, and an extension temperature of $72^{\circ} \mathrm{C} \mathrm{for}$ $60 \mathrm{~s}$; and final extension at $72^{\circ} \mathrm{C}$ for $10 \mathrm{~min}$. The PCR products were electrophoresed on an $8 \%$ polyacrylamide denaturing gel and visualized using silver staining (Creste et al., 2001). A 50 bp ladder (Sangon Biotech Co., Ltd) was used as a size standard.

\section{EST-SSR genotyping and data analysis}

A total of 183 EST-SSR primers were tested to assess polymorphisms among six accessions (P. nigrum 'Reyin-1', P. nigrum 'BNYE-1', P. hainanense, Piper laetispicum, and Piper hancei). Finally, 13 primer pairs with clear and stable banding patterns were used to analyze the genetic diversity of black pepper germplasms. The presence (1) or absence (0) of bands in each individual plant was visually scored. Faint bands were excluded. POPGENE v. 1.32 was used to calculate the mean Nei's (1978) genetic diversity $(H)$ and the Shannon diversity index $(I)$ was used to estimate the level of genetic variation (Yeh et al., 1997). The polymorphism information content (PIC) was used to represent the richness of alleles for markers in each population. The PIC values were calculated, based on the formula given by Botstein et al. (1980). Genetic similarities were analyzed with Numerical Taxonomy and Multivariate Analysis System (NTSYS-pc) v. 2.0 (Rohlf, 1998). Clustering analysis was conducted using the unweighted pair group method with arithmetic mean (UPGMA).

\section{RESULTS}

\section{Characterization of EST-SSRs in the germplasm of black pepper}

The allelic diversity was measured in 148 black pepper germplasms. All loci were polymorphic, revealing single locus profiles. The 13 SSR markers detected 160 alleles, in total. The number of alleles per locus ranged from 10 (PE06, PN03, and PE14) to 19 (PN04), with an average of 12.31 alleles per marker. An example of allelic polymorphism is shown in Figure 1. The 13 selected UniGene sequences harbored di- and tri-nucleotide motifs. The BLASTn tool was employed to determine the putative functions of these UniGenes. Of the UniGenes, seven showed significant homology to signal transduction and transcription, general metabolism, binding function, and subcellular localization related genes (Table 1).

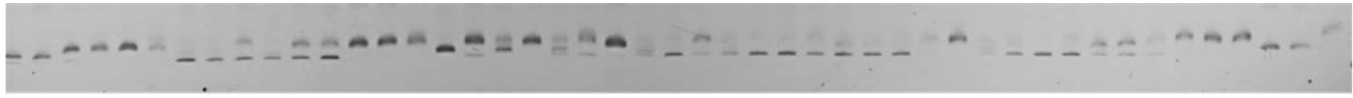

Figure 1. Banding patterns generated by EST-SSR markers, using primer PE02.

\section{Polymorphism of EST-SSRs in the germplasm of black pepper}

Based on the origin of the germplasm, all accessions except $P$. pellucida were divided into three groups (American, Asian wild, and cultivated accessions) to analyze marker polymorphisms. In these groups, $H$ ranged from 0.07 to 0.13 , with an average of 0.10 and $/$ ranged from 0.14 to 0.23 , with an average of 0.18 . The Asian wild accessions showed the highest $H$ and $I$, whereas the cultivated accessions showed the lowest. In general, the genetic diversity trend of the three groups was Asian wild accessions > America accessions > cultivated accessions. The cultivated accessions showed the lowest genetic diversity compared to both the Asian wild and the America accessions. 
Table 1. Primer sequences and characterization for 13 EST-SSR loci from black pepper germplasms.

\begin{tabular}{|c|c|c|c|c|c|c|c|}
\hline Locus & Primer sequence & $\begin{array}{c}\text { Repeat } \\
\text { motifs }\end{array}$ & $\begin{array}{c}\text { Target } \\
\text { size (bp) }\end{array}$ & $\mathrm{Ta}\left({ }^{\circ} \mathrm{C}\right)$ & $\begin{array}{c}\text { Origin of } \\
\text { isolated libraries }\end{array}$ & Homologues of gene name & E-value \\
\hline$\overline{P E 15}$ & $\begin{array}{l}\text { F: GTGTTACCTTTGGGGCATTCA } \\
\text { R: TGTGTCAGGGCATCAAACC }\end{array}$ & $(\mathrm{GT})_{13}$ & 130 & 55 & PN & - & - \\
\hline $\begin{array}{l}\text { PE02 } \\
r\end{array}$ & $\begin{array}{l}\text { F: AGGGATGCTTGCATTGAGTATAG } \\
\text { R: TGAATGGTGAACTCTCGTATGTG }\end{array}$ & $\mathrm{AG}\left(2^{*} 10\right)$ & 147 & 55 & $\mathrm{PN}, \mathrm{PF}$ & Uncharacterized protein [Mycobacterium tuberculosis] & 0.007 \\
\hline PN01 & $\begin{array}{l}\text { F:CATACTACGGGGTAAAACACCAA } \\
\text { R:CCGGCATCTCTATTTGACTAGATT }\end{array}$ & GT $\left(2^{*} 9\right)$ & 154 & 55 & PN & $\begin{array}{l}\text { Ribonuclease E/G-like protein, chloroplastic isoform X1 } \\
\text { [Nelumbo nucifera] }\end{array}$ & $7 \mathrm{E}-31$ \\
\hline 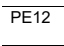 & $\begin{array}{l}\text { F: CCGGCATCTCTATTTGACTAGATT } \\
\text { R: TCTTCCTCCTGCTTCTTTTGAG }\end{array}$ & $\mathrm{TG}(2 * 10)$ & 155 & 55 & $\mathrm{PN}$ & Arginine decarboxylase [Malus domestica] & 0 \\
\hline PE07 & $\begin{array}{l}\text { F: GTTGGAGATTTCATTTGTCTTGC } \\
\text { R: TATCGGAATTTGTTTGTCGACTC }\end{array}$ & $\mathrm{TA}\left(2^{\star} 7\right)$ & 140 & 55 & $\mathrm{PF}$ & - & - \\
\hline PE06 & $\begin{array}{l}\text { F: ATAGAGTGACCGAAAAGACTCGG } \\
\text { R: CATTTCCATTGAAGGTAGAAGGA }\end{array}$ & СТT $\left(3^{*} 5\right)$ & 160 & 55 & PN, PF & Thioredoxin z, P,TRX z isoform 1 [Theobroma cacao] & 0 \\
\hline PN02 & $\begin{array}{l}\text { F: GTCGTCATGTGCGATGTCTC } \\
\text { R: AGGTGATGTAGTGGTTCTTGCG }\end{array}$ & $\operatorname{CCG}\left(3^{*} 5\right)$ & 160 & 53 & $\mathrm{PN}$ & $\begin{array}{l}\text { Signal peptide peptidase-like } 2 \text { isoform } 1 \text { [Theobroma } \\
\text { cacao] }\end{array}$ & 0 \\
\hline PN03 & $\begin{array}{l}\text { F: CCTTGATGCAAAACCTCATAGAA } \\
\text { R: TGAAAATTAAAAGCGTGATAGGA }\end{array}$ & $\operatorname{CAT}\left(3^{*} 7\right)$ & 152 & 53 & $\mathrm{PN}$ & - & - \\
\hline 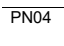 & $\begin{array}{l}\text { F: GAATATGCGTATCGGAGATCAAA } \\
\text { R: AAGTGGAGAAGAAATCTGAAGCA }\end{array}$ & $\operatorname{CTC}\left(3^{*} 7\right)$ & 149 & 53 & $\mathrm{PN}$ & - & - \\
\hline 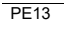 & $\begin{array}{l}\text { F: GAACCTCTCACCACCACTCAAC } \\
\text { R: ATCATCAAAGGACGAGGAATTG }\end{array}$ & $\mathrm{GCT}\left(3^{*} 6\right)$ & 147 & 53 & $\mathrm{PN}, \mathrm{PF}$ & Membrane protein-like protein [Glycine max] & $1 \mathrm{E}-80$ \\
\hline PL01 & $\begin{array}{l}\text { F: TTGTTGCATCTGGATTTGTAGTG } \\
\text { R: TACAAGAAAACCCAGGAAGATGA }\end{array}$ & GGT(3*7) & 145 & 53 & PF & Putative clathrin assembly protein [Glycine soja] & 0 \\
\hline PL02 & $\begin{array}{l}\text { F: AAGATCAAACCAGTGAAGGTGAA } \\
\text { R: TTAAATGCATGCTCTTGCCTAAT }\end{array}$ & $\operatorname{ATC}\left(3^{*} 6\right)$ & 135 & 53 & $\mathrm{PF}$ & - & - \\
\hline PE14 & $\begin{array}{l}\text { F: GATCAAGAGAATCGTAGCAGCAG } \\
\text { R: GTCGGAATCATGTCTTCTAATCG }\end{array}$ & ATG $\left(3^{*} 7\right)$ & 157 & 53 & $\mathrm{PN}, \mathrm{PF}$ & Cyclin-L1, putative [Ricinus communis] & $7.00 \mathrm{E}-92$ \\
\hline
\end{tabular}

PN = Piper nigrum; PF = Piper flaviflorum .

The PIC values varied between 0.91 and 0.95 , with a mean of 0.93 (Table 2) and the highest PIC being found in the black pepper germplasms. The Asian wild accessions produced the highest number of alleles. For example, PE14 produced 10 putative alleles, of which 2, 10, and 4 alleles were detected in American, Asian wild, and cultivated accessions, respectively. The three groups typically shared the same alleles. In the case of the PN03 locus, the American accessions shared $60 \%$ of the bands with the Asian wild accessions and the cultivated accessions shared $100 \%$ bands with the Asian wild accessions. Some alleles were rarely detected in the panel. For instance, the amplified fragments of PN04-14 and PE15-9 were specifically detected in PL and QSHJ-NG. Furthermore, some alleles were preferentially present in certain groups. For example, PE02-5 and PE02-6 were specifically present in the Asian wild accessions, whereas PL02-8 was present in the American accessions. A high percentage of PN01-4 was specifically present in the cultivated accessions.

Table 2. Characterization of polymorphic EST-SSR loci in black pepper germplasms.

\begin{tabular}{l|c|c|c|c|c}
\hline Locus & PIC & Central American accessions & Asian wild accessions & Cultivated accessions & Number of alleles detected \\
\hline PE15 & 0.93 & 3 & 11 & 4 & 11 \\
\hline PE02 & 0.93 & 6 & 9 & 6 & 11 \\
\hline PN01 & 0.94 & 7 & 12 & 4 & 14 \\
\hline PE12 & 0.93 & 5 & 10 & 6 & 12 \\
\hline PE07 & 0.93 & 2 & 11 & 8 & 11 \\
\hline PE06 & 0.91 & 3 & 8 & 2 & 10 \\
\hline PN02 & 0.93 & 4 & 12 & 6 & 10 \\
\hline PN03 & 0.91 & 4 & 9 & 3 & 19 \\
\hline PN04 & 0.95 & 8 & 17 & 6 & 11 \\
\hline PE13 & 0.92 & 4 & 11 & 4 & 14 \\
\hline PL01 & 0.92 & 4 & 14 & 4 & 15 \\
\hline PL02 & 0.94 & 12 & 12 & 4 & 10 \\
\hline PE14 & 0.94 & 2 & 10 & 63 & 160 \\
\hline Total & & 64 & 146 & 4.85 & 12.31 \\
\hline Mean & 0.93 & 4.92 & 11.23 & & \\
\hline
\end{tabular}




\section{Genetic relationship among genotypes in the germplasm of black pepper}

The calculated genetic similarity coefficients of the panel accessions ranged from 0.724 to 1.000 , with a mean of 0.867 . The minimum coefficient of genetic similarity was found between HSJ-LY and YX003, whereas the maximum coefficient was found between PC001 and PC008. Moreover, the genetic similarity coefficients were the smallest between $P$. pellucida $(\mathrm{CHJ}-\mathrm{WN})$ and all other accessions, with an average of 0.787 . The coefficients were higher among varieties, with an average of 0.914 .

A dendrogram of the genetic relationships was constructed, using the UPGMA method. As shown in Figure 2, at the genetic similarity of 0.835 , two major clades were classified: the Neotropics and the Asian tropics. The Neotropic clade included all wild accessions from the Americas. Seven accessions that originated from the Americas formed a subcluster and three Piper umbellatum accessions fell into another subcluster. The Asian tropics clade included all 104 wild accessions from tropical Asian and all varieties from different countries. The wild and cultivated accessions were separated at a genetic similarity of 0.842 . The wild species that came from different locations clustered together, except for $P$. laetispicum and Piper austrosinense. In general, the genetic basis of the cultivated accessions tended to be narrow. As the only representative of the genus Peperomia, $P$. pellucida was separated from the rest of the accessions at a genetic similarity of 0.782 .

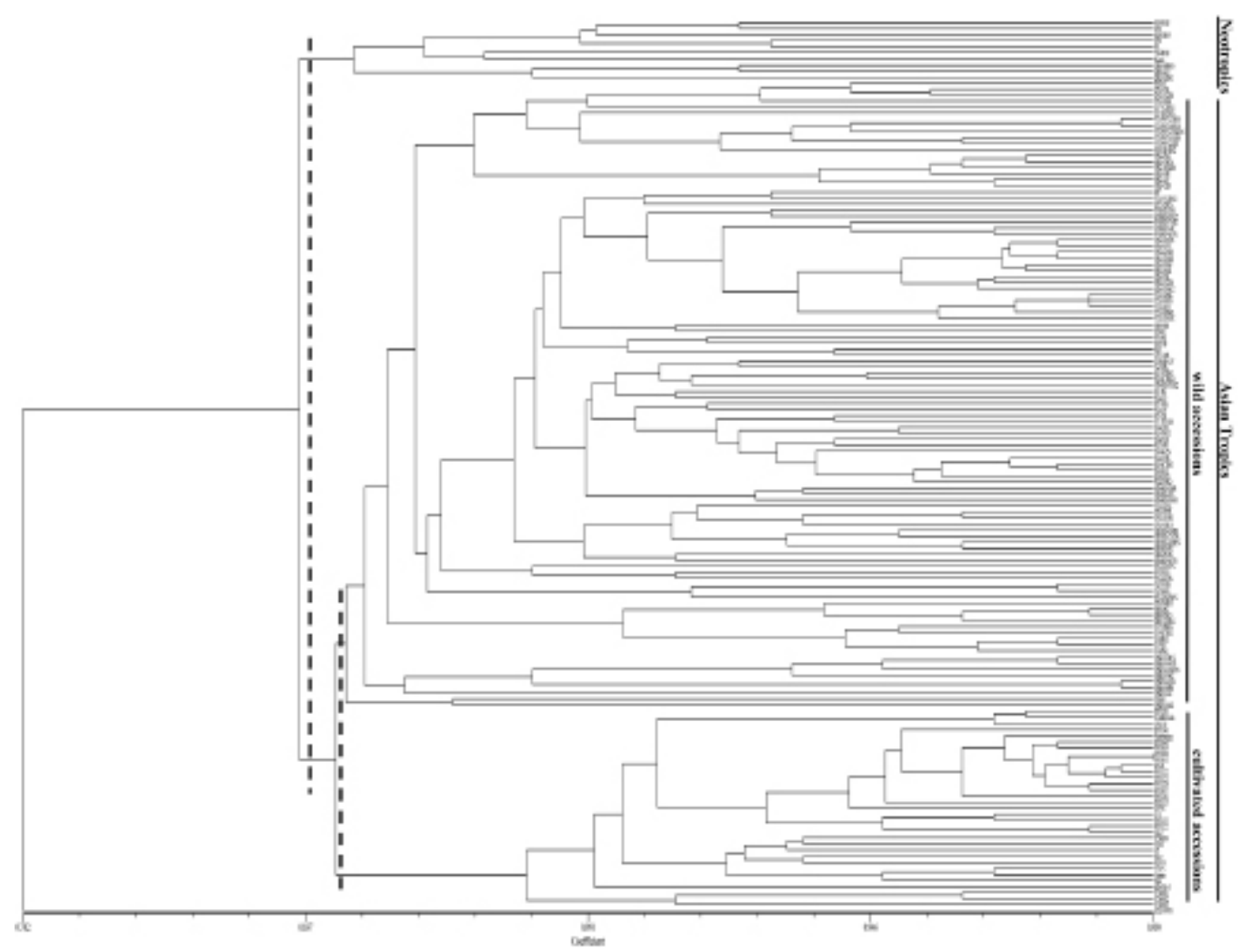

Figure 2. Dendrogram of 148 black pepper germplasms resulting from an UPGMA analysis based on Nei's genetic distance. 
Among all the amplified alleles of the American accessions, $17.46 \%$ were specific to the Neotropics clade. Furthermore, the Neotropic and the Asian tropic clades shared the same advantage alleles in all EST-SSR markers. The same situation was also found in the wild and cultivated accessions. Furthermore, PN01-4 was presented in 33 cultivated accessions, but only in eight wild accessions, suggesting it was more specific to the cultivated accessions.

\section{DISCUSSION}

Because of the characters of high abundance, codominant inheritance, and whole genome coverage, SSR has become a favored molecular marker. Studies have shown that SSRs are very useful for crop improvement in many species (Gupta and Varshney, 2000). Compared with ESTSSRs, most gSSRs (genomic SSRs) are derived from the intergenic regions of the genomic BAC library, which usually have no gene function. In addition, developing gSSR markers is complex, difficult, and costly (Wang et al., 2010). With the development of sequencing technology, ESTSSRs have been successfully applied in various crops, such as Gossypium (Wang et al., 2015), grape (Scott et al., 2000), coffee (Combes et al., 2000), rubber tree (Feng et al., 2009), and tomato (Zhou et al., 2015). Because there are few available public sequence databases for black pepper or closely related species, it is difficult to develop gSSR primers (Joy et al., 2011). Based on the rapid development of next-generation sequencing technologies, it is now feasible to develop molecular markers even for non-model organisms (Gardner et al., 2011; Zalapa et al., 2012).

This is the first study of genetic diversity using EST-SSRs in black pepper germplasm, which illustrated that it is feasible and convenient to develop EST-SSRs for black pepper. ESTSSRs are highly valuable resources for various applications, such as phylogenetic studies of the genus Piper and black pepper breeding. This paper presents the utilization of EST microsatellite DNA to investigate the level of genetic diversity in black pepper germplasms. The EST-SSRs showed high polymorphism, identified as high $I$ and $H$ values. In a previous study, the number of markers was shown to be similar to that found in 40 popular cultivars and four species of black pepper in the southern region of India, with the number of alleles per marker ranging from 6 to 33 and a mean of 15.5 (Joy et al., 2011). The average PIC value, which indicates the discriminatory power of a DNA marker, was higher than that found in 40 popular genotypes and four species of black pepper (0.85; Joy et al., 2011). The ISSR markers gave high values of effective number of alleles $=1.521$ and $H=0.312$ among 10 wild species and three cultivated accessions from Hainan, China (Jiang and Liu, 2011a). These results suggest that black pepper germplasms possess a complex genetic background and a high genetic diversity. We believe that the characteristics of the genus Piper, such as dioecious plants, wind pollination, and ancient origins, are the main reasons of the high levels of genetic variation observed.

The two clades presented here are in agreement with the genetic and geographic distances. The genus Piper has been divided into three major clades: the Neotropics, the Asian tropics and the South Pacific, based on the ITS of nuclear ribosomal DNA (Jaramillo and Manos, 2001; Jaramillo et al., 2008). The Asian tropics and the South Pacific clades were combined to a Paleotropical clade by Wanke et al. (2007). The major clades identified here correspond to the description of Jaramillo and Manos (2001). Although the Neotropic clade showed some specific alleles, it shared the same advantage alleles as the Asian tropics clade. The reason for this may be that they originated from south India but belonged to different geographical distributions. However, the paraphyly of the taxa did not show a geographic distribution in the Asian tropics clades. QSHJXSBN and QSHJ-BB, collected from Yunnan, clustered with Piper thomsonii from Hainan and 
Guangxi. QSHJ-LC, from Yunnan, clustered separately. The species collected from Hainan and other provinces did not cluster together, suggesting that species of the genus Piper with different geographic origins probably have at least some common genetic basis as a consequence of gene flow. Hence, it is worth to perform further studies of the Asian tropics clades. The cultivated accessions did not group strictly by origin or parents. PC and YX, hybridized by BNYE-1 and RY1 , grouped separately. The hybrids possessed more distant genetic similarity with other cultivated accessions, which illustrates that the genetic variation was broaden by hybridization.

Black pepper, one of the most important spices in the genus Piper, originated in the evergreen forests of the Western Ghats in south India. In the present study, the Asian tropics and the cultivar clades clustered together at a genetic similarity of 0.842 . The close relationship between the cultivated and the Asian wild accessions verified the origin of black pepper. Until now, there are few studies revealing the origin of $P$. nigrum. Three species (Piper galeatum, Piper wightii, and Piper trichostachyon) have been considered the putative parents of $P$. nigrum based on morphological and biosystematic studies (Ranvindran, 1991). The average genetic similarity coefficients $(0.875)$ between $P$. flaviflorum and the cultivated accessions showed a close relationship. Black pepper is the product of artificial selection. The closely related wild species are better for expanding the genetic basis of black pepper. The wild species that displayed a close genetic relationship with the cultivated accessions may be useful for further breeding and grafting of black pepper. The excellent genetic resource in the wild species could be transferred to cultivars for black pepper genetic improvement.

\section{Conflicts of interest}

The authors declare no conflict of interest.

\section{ACKNOWLEDGMENTS}

Research financially supported by the National Natural Science Foundation of China (\#31201263), and the "948" project of the Agricultural Department (\#2011-G13(5)-1). We gratefully acknowledge the efforts of Dr. Fupeng Li for reading and editing the English version of the manuscript.

\section{REFERENCES}

Anandaraj M (2000). Diseases of black pepper. In: Black pepper (Ranvindran PN, ed.). Harwood Academic Publishers, Amsterdam, 239-267.

Botstein D, White RL, Skolnick M and Davis RW (1980). Construction of a genetic linkage map in man using restriction fragment length polymorphisms. Am. J. Hum. Genet. 32: 314-331.

Combes MC, Andrzejewski S, Anthony F, Bertrand B, et al. (2000). Characterization of microsatellite loci in Coffea arabica and related coffee species. Mol. Ecol. 9: 1178-1180. http://dx.doi.org/10.1046/j.1365-294x.2000.00954-5.x

Creste S, Tulmann Neto A and Figueira A (2001). Detection of single sequence repeat polymorphisms in denaturing polyacrylamide sequencing gels by silver staining. Plant Mol. Biol. Rep. 19: 299-306. http://dx.doi.org/10.1007/ BF02772828

Fan R, Wu HS, Hao CY, Tan LH, et al. (2014). Genetic diversity of pepper germplasm resources by ISSR markers. Chin. J. Trop. Crops 35: 1-7.

Fan R, Ling P, Hao CY, Li FP, et al. (2015). Construction of a cDNA library and preliminary analysis of expressed sequence tags in Piper hainanense. Genet. Mol. Res. 14: 12733-12745. http://dx.doi.org/10.4238/2015.October.19.17

Feng SP, Li WG, Huang HS, Wang JY, et al. (2009). Development, characterization and cross-species/genera transferability of EST-SSR markers for rubber tree (Hevea brasiliensis). Mol. Breed. 23: 85-97. http://dx.doi.org/10.1007/s11032-008$\underline{9216-0}$ 
Gardner MG, Fitch AJ, Bertozzi T and Lowe AJ (2011). Rise of the machines--recommendations for ecologists when using next generation sequencing for microsatellite development. Mol. Ecol. Resour. 11: 1093-1101. http://dx.doi.org/10.1111/j.17550998.2011.03037.x

Gupta PK and Varshney RK (2000). The development and use of microsatellite markers fore genetic analysis and plant breeding with emphasis on bread wheat. Euphytica 113: 163-185. http://dx.doi.org/10.1023/A:1003910819967

Howard RA (1973). Notes on the Piperaceae of the Lesser Antilles. J. Arnold Arbor. 54: 377-411. http://dx.doi.org/10.5962/bhl. part. 4827

Hu L, Hao C, Fan R, Wu B, et al. (2015). De novo assembly and characterization of fruit transcriptome in black pepper (Piper nigrum). PLoS One 10: e0129822. http://dx.doi.org/10.1371/journal.pone.0129822

Jaramillo MA and Manos PS (2001). Phylogeny and patterns of floral diversity in the genus Piper (Piperaceae). Am. J. Bot. 88: 706-716. http://dx.doi.org/10.2307/2657072

Jaramillo MA, Callejas R, Davidson C, Smith JF, et al. (2008). A phylogeny of the tropical genus Piper using ITS and the chloroplast intron psbJ-petA. Syst. Bot. 33: 647-660. http://dx.doi.org/10.1600/036364408786500244

Jiang Y and Liu JP (2011a). Analysis of genetic diversity of Piper spp. in Hainan Island (China) using inter-simple sequence repeat ISSR markers. Afr. J. Biotechnol. 10: 14731-14737. http://dx.doi.org/10.5897/AJB11.2342

Jiang Y and Liu JP (2011b). Evaluation of genetic diversity in Piper spp using RAPD and SRAP markers. Genet. Mol. Res. 10: 2934-2943. http://dx.doi.org/10.4238/2011.November.29.4

Joy N, Prasanth VP and Soniya EV (2011). Microsatellite based analysis of genetic diversity of popular black pepper genotypes in South India. Genetica 139: 1033-1043. http://dx.doi.org/10.1007/s10709-011-9605-x

Liu Y, Yadev VR, Aggarwal BB and Nair MG (2010). Inhibitory effects of black pepper (Piper nigrum) extracts and compounds on human tumor cell proliferation, cyclooxygenase enzymes, lipid peroxidation and nuclear transcription factor-kappa-B. Nat. Prod. Commun. 5: 1253-1257.

Nei M (1978). Estimation of average heterozygosity and genetic distance from a small number of individuals. Genetics 89: $583-590$. Nishimura Y, Kitagishi Y, Yoshida H, Okumura N, et al. (2011). Ethanol extracts of black pepper or turmeric down-regulated SIRT1 protein expression in Daudi culture cells. Mol. Med. Rep. 4: 727-730.

Ranvindran PN (1991). Studies in black pepper and some of its wild relatives. Doctoral thesis, Department of Botany, University of Calicut.

Ranvindran PN (2000). Introduction In: Black pepper (Ravindran PN, ed.). Harwood Academic Publishers, Amsterdam, 1-22.

Rohlf FJ (1998). NTSYS-pc: Numerical taxonomy and multivariate analysis system, version 2.0. Applied Biostatistics Inc., New York.

Scott KD, Eggler P, Seaton GG, Rossetto M, et al. (2000). Analysis of SSRs derived from grape ESTs. Theor. Appl. Genet. 100: 723-726. http://dx.doi.org/10.1007/s001220051344

Wang BH, Rong P, Cai XX, Wang W, et al. (2015). Development of EST-SSR markers related to disease resistance and their application in genetic diversity and evolution analysis in Gossypium. Genet. Mol. Res. 14: 10630-10644. http://dx.doi. org/10.4238/2015.September.9.4

Wang JY, Pan LJ, Yang QG and Yu SL (2010). Development and characterization of EST-SSR markers from NCBI and cDNA library in cultivated peanut (Arachis hypogaea L.). Mol. Plant Breed. 1: 806-810.

Wanke S, Jaramillo MA, Borsch T, Samain MS, et al. (2007). Evolution of Piperales--matK gene and trnK intron sequence data reveal lineage specific resolution contrast. Mol. Phylogenet. Evol. 42: 477-497. http://dx.doi.org/10.1016/j. ympev.2006.07.007

Wu BD, Hao CY, Fan R, Yang JF, et al. (2015). Development and application of EST-SSR markers in pepper. Chin. J. Trop. Crops 36: 237-243.

Wu HS, Yang JF and Lin LY (2009). A summary of pepper research in China. Sci. Agric. Sinica 42: 2469-2480.

Yeh FC, Yang RC, Boyle TBJ, Ye ZH, et al. (1997). POPGENE, the user-friendly shareware for population genetic analysis. Molecular Biology and Biotechnology Centre, University of Alberta, Canada.

Zalapa JE, Cuevas H, Zhu H, Steffan S, et al. (2012). Using next-generation sequencing approaches to isolate simple sequence repeat (SSR) loci in the plant sciences. Am. J. Bot. 99: 193-208. http://dx.doi.org/10.3732/ajb.1100394

Zhang GW, Xu SC, Mao WH, Gong YM, et al. (2013). Development of EST-SSR markers to study genetic diversity in hyacinth bean (Lablab purpureus L.). Plant Omics 6: 295-301.

Zhou R, Wu Z, Jiang FL and Liang M (2015). Comparison of gSSR and EST-SSR markers for analyzing genetic variability among tomato cultivars (Solanum lycopersicum L.). Genet. Mol. Res. 14: 13184-13194. http://dx.doi.org/10.4238/2015. October.26.14

\section{Supplementary material}

Table S1. List of 148 accessions of black pepper germplasm in this study. This file contains a table that lists the name, origin, and groups of the 148 accessions of black pepper germplasms used in this study. http://www.geneticsmr.com/year2016/vol15-1/pdf/gmr8099_supplementary.pdf 